\title{
Clinical and laboratory characteristics, staging, and outcomes of individuals with AIDS-associated Kaposi's sarcoma at an university hospital*
}

\author{
Catarina Tenório de Lima ${ }^{1}$ \\ Heberton Medeiros de Teixeira ${ }^{4,5}$ \\ Vera Magalhães da Silveira ${ }^{2}$
}

\author{
Paulo Sérgio Ramos de Araújo ${ }^{2,3}$ \\ Josemir Belo dos Santos 2,6
}

DOI: http:/ / dx.doi.org/10.1590/abd1806-4841.20175377

\begin{abstract}
BACKGround: Kaposi's sarcoma continues to be the most common human immunodeficiency virus - associated neoplasm with considerable morbidity and mortality.

Овлестіvе: To describe the clinical and laboratory characteristics, initial staging, and outcomes of aids patients with Kaposi's sarcoma at an university hospital of Recife, Pernambuco.

Methods: This is a descriptive study with analytic character, retrospective, of a case series between 2004 and 2014.

RESULTS: Of the 22 patients included in the study, 20 were aged $<40$ years $(72.7 \%)$. The majority had CD $4+\mathrm{T}$ lymphocyte counts of $<200$ cells $/ \mathrm{mm}^{3}$ (77.3\%) and human immunodeficiency virus loads of $<100,000$ copies $/ \mathrm{mL}$ (78.9\%). Lesions were most commonly observed on the skin $(90 \%)$, and internal organs were affected in 11 of the 22 patients. Only 7 (31.8\%) of the 22 patients were undergoing antiretroviral therapy (ART) at the time of Kaposis sarcoma diagnosis, and the initial disease staging classification was high risk (Aids Clinical Trials Group Oncology Committee) in 19 of the 22 patients (86.4\%). Regarding Kaposi's sarcoma treatment, 17 of 22 patients $(77.3 \%)$ underwent systemic chemotherapy + ART and 5 were treated exclusively with ART. Eight of the 22 patients died (36.5\%); of these, $87.5 \%$ had died within one year of Kaposi's sarcoma diagnosis.

LIMITATION OF THE STUDY: Without a control group, this study cannot be used to generate hypotheses.

ConClusions: Despite the association between aids and late Kaposi's sarcoma diagnosis in the study population, including an unfavorable risk at the time of staging, a lower mortality rate was observed relative to other studies; this might be related to access to a specialized health service.
\end{abstract}

Keywords: Acquired immunodeficiency syndrome; HIV; Neoplasms; Sarcoma, Kaposi

\section{INTRODUCTION}

AIDS-associated Kaposi's sarcoma (KS) remains a serious public health problem in emerging countries, with a high mortality rate, even in patients presenting the cutaneous form of the disease. ${ }^{1}$ Before the advent of antiretroviral therapy (ART), KS was 20,000 times more common in AIDS patients than in the general population. ${ }^{2}$ Currently, the incidence of KS has decreased dramatically in the United States and Europe. However, it remains the second most frequent tumor in patients infected with the human immunodeficiency virus (HIV) in the world, being the most common cancer in sub-Saharan Africa. ${ }^{3-5}$

The World Health Organization (WHO) estimated that about 5 million people infected with HIV would be receiving ART in sub-Saharan Africa by the end of 2010, with an estimated coverage rate of $56 \%$ of patients. ${ }^{6}$ ART has been used successfully in the treatment of KS in the earliest stages, thus reducing the mortality of this neoplasia.

In Brazil, some researchers published data about the clinical-epidemiological characteristics, as well as the geopolitical distribution of KS in the different regions of the country, however, we did not observe, in these studies, the inclusion of the clinical follow-up of the patients. ${ }^{7,8}$ Therefore, this study intends to fill these gaps, reporting the clinical-laboratory characteristics, initial staging according to the AIDS Clinical Trials Group Oncology Committee (ACTG) and what the clinical outcome of these patients.

\footnotetext{
Received on 14.11.2015.

Approved by the Advisory Board and accepted for publication on 06.04.2016.

* Study conducted at Hospital das Clínicas da Universidade Federal de Pernambuco (UFPE) - Recife (PE), Brazil

Financial support: None.

Conflict of interest: None.

Commission and Hospital Infection Control Service of the Hospital Barão de Lucena - Recife (PE), Brazil.

Department of Tropical Medicine - Universidade Federal de Pernambuco (UFPE) - Recife (PE), Brazil.

Ageu Magalhães Research Center - Fundação Oswaldo Cruz (CPqAM-Fiocruz) - Recife (PE), Brazil.

Department of Clinical Oncology - Real Hospital Português de Beneficência de Pernambuco - Recife (PE), Brazil.

Department of Clinical Oncology - Hospital Barão de Lucena - Recife (PE), Brazil.

Dermatology Service of the Hospital das Clínicas of the Universidade Federal de Pernambuco (HC-UFPE) - Recife (PE), Brazil.
} 


\section{METHODS}

A retrospective, descriptive study with an analytical character, case series, conducted between 2004 and 2014, at the Hospital das Clínicas de Recife-Pernambuco, which attends patients in the public healthcare system - Sistema Único de Saúde (SUS).

Patients aged 18 years or older with AIDS and histopathological examination demonstrating Kaposi's sarcoma were included. The study was approved by the Research Ethics Committee of the University Health Sciences Center.

A specific form was used, containing the following variables: age, sex, T-CD4+ cell count, viral load, lesion classification, most affected organs, ART use, presence of B symptoms, opportunistic infection, treatment with exclusive ART or chemotherapy + ART, which chemotherapy medications were used and the clinical outcome.

Patients included in the study were organized into two groups during the classification of staging by ACTG. The first was by individuals who were already using ART at the time of diagnosis of Kaposi's sarcoma and the second by patients with a recent diagnosis of HIV infection who had not yet started ART or by those who dropped out treatment.

The description of the characteristics of the study population was presented by frequency distribution. In the analysis of the associations regarding the use of ART, the variables were tested by Fisher's exact test. The significance of the test was $5 \%(p<0.05)$. The software used in the analysis was STATA, version 12.0.

\section{RESULTS}

Twenty-two patients were included in the study, 20 (90.9\%) of them were men and the majority aged $<40$ years $(72.7 \%)$. In $77.3 \%$ (17) of the investigated cases, the T-CD4+ cell count was below 200 cells $/ \mathrm{mm}^{3}$, noting that nine patients had a diagnosis of AIDS concomitant with the diagnosis of KS, as well as HIV viral load $<100,000$ copies/mL was present in $78.9 \%$ (15) of the patients, whereas only one case had an undetectable viral load (Table 1).

In $90.0 \%(20 / 22)$ of the cases, KS lesions involved the skin, and, in addition to these cutaneous lesions, half of the patients (11) had organ involvement. Only one case (4.5\%) presented minimal oral lesion, and in four cases $(18.18 \%$ ) patients had extensive oral lesions, some of them vegetative. The organs most affected were the stomach and intestines. Previous opportunistic infections were identified in seven cases and, at the time of diagnosis, in 16 cases $(72.7 \%)$, and oroesophageal candidiasis was more frequent both at the time of diagnosis and in the diagnosis. Of the nine patients who had a diagnosis of AIDS concomitant to the diagnosis of KS, eight also had an opportunistic infection. In $77.3 \%$ of the cases, B symptoms were found, and only seven patients used ART at the time of KS diagnosis (Table 2).

Regarding Kaposi's sarcoma treatment, 17 (77.3\%) of the 22 patients underwent chemotherapy + ART, and the remaining five, exclusive ART. There was no record of irradiation, intralesional or surgery treatment. Liposomal doxorubicin and bleomycin-vincristine (BV) were the most commonly used medications, with a case of adriamycin-bleomycin-vincristine (ABV) and paclitaxel; in two patient records, no information regarding medications was found (Table 3).

Of the 22 patients studied, 19 (86.4\%) had initial staging of the high-risk disease, of which, $71.4 \%$ were using ART, and $93.3 \%$
TABLE 1: Laboratory characteristics of patients with Kaposi's sarcoma living with HIV/AIDS, attended at an university hospital between 2004 and 2014

\begin{tabular}{lll} 
Characteristics & Number & $\%$ \\
\hline $\begin{array}{l}\text { HIV-Related lab exams } \\
\text { T-CD4+ lymphocyte count }\left(\text { cell/mm } \text { mm }^{3}\right)\end{array}$ & & \\
$\quad>350$ & 2 & 9.1 \\
$200-349$ & 3 & 13.6 \\
$\quad<200$ & 17 & 77.3 \\
Viral load count & & \\
$\quad$ Undetectable & 1 & 4.5 \\
$\quad<100,000$ copies & 15 & 68.2 \\
$\quad>100,000$ copies & 3 & 13.6 \\
Unknown & 3 & 13.6
\end{tabular}

Note: ${ }^{a}$ Information ignored - not on medical chart.

TABLE 2: Main clinical manifestations of patients with Kaposi's sarcoma living with HIV/AIDS, attended at an university hospital between 2004 and 2014

\begin{tabular}{|c|c|c|}
\hline Characteristics & Number & $\%$ \\
\hline \multicolumn{3}{|l|}{ Classification of lesions ${ }^{b}$} \\
\hline Skin & 20 & 90.9 \\
\hline Minimal oral lesion (hard palate) & 1 & 4.5 \\
\hline Extensive oral lesion & 4 & 18.8 \\
\hline Organs & 11 & 50.0 \\
\hline Skin + Organs & 6 & 27.3 \\
\hline Skin + Organs + Extensive oral lesion & 3 & 13.6 \\
\hline \multicolumn{3}{|l|}{ Most affected organs ${ }^{b}$} \\
\hline Stomach & 8 & 53.3 \\
\hline Colon & 3 & 20.0 \\
\hline Lung & 2 & 13.3 \\
\hline Spleen & 1 & 6.7 \\
\hline Liver & 1 & 6.7 \\
\hline \multicolumn{3}{|l|}{ Prior opportunistic infection } \\
\hline No & 15 & 68.2 \\
\hline Yes $^{\mathrm{b}}$ & 7 & 31.8 \\
\hline Oroesophageal candidiasis & 4 & 57.1 \\
\hline Herpes zoster & 2 & 28.6 \\
\hline Neurotoxoplasmosis & 1 & 14.3 \\
\hline Pulmonary tuberculosis & 1 & 14.3 \\
\hline \multicolumn{3}{|c|}{$\begin{array}{l}\text { Opportunistic infection at the time of diagnosis of Kaposi's } \\
\text { sarcoma }\end{array}$} \\
\hline No & 6 & 27.3 \\
\hline Yes $^{\mathrm{b}}$ & 16 & 72.7 \\
\hline Oroesophageal candidiasis & 7 & 43.7 \\
\hline Pulmonary and extrapulmonary tuberculosis & 4 & 25.0 \\
\hline Neurotoxoplasmosis & 3 & 18.7 \\
\hline Neurotoxoplasmosis & 2 & 12.5 \\
\hline Pneumocystosis & 1 & 6.2 \\
\hline \multicolumn{3}{|l|}{ B symptoms } \\
\hline Yes & 17 & 77.3 \\
\hline No & 5 & 22.7 \\
\hline \multicolumn{3}{|l|}{ Use of ART at the diagnosis of Kaposi's sarcoma } \\
\hline No & 15 & 68.2 \\
\hline Yes & 7 & 31.8 \\
\hline Protease inhibitors & 2 & 28.6 \\
\hline Non-nucleoside analogue reverse & 5 & 71.4 \\
\hline Transcriptase inhibitor & & \\
\hline
\end{tabular}

Note: ${ }^{b}$ Not mutually exclusive categories 
TABLE 3: Characteristics related to the treatment of Kaposi's sarcoma of patients living with HIV AIDS, attended at an university hospital between the years 2004 and 2014

\begin{tabular}{lll} 
Characteristics & Number & $\%$ \\
\hline $\begin{array}{lll}\text { Kaposi's sarcoma treatment } \\
\text { ART }\end{array}$ & 5 & 22.7 \\
$\quad$ Chemotherapy + ART & 17 & 77.3 \\
Chemotherapy drugs & & \\
$\quad$ Liposomal doxorubicin & 7 & 31.8 \\
BV (bleomycin and vincristine) & 6 & 50.0 \\
ABV (adriamycin. bleomycin and vincristine) & 1 & 4.5 \\
Paclitaxel & 1 & 4.5 \\
Unknown $^{\text {a }}$ & 2 & 9.1
\end{tabular}

Note: ${ }^{a}$ Unknown information - not on medical chart.

TABLE 4: Association of staging and outcome of Kaposi's sarcoma cases and ART use of patients living with HIV/AIDS, attended at an university hospital between the years 2004 and 2014

\begin{tabular}{|c|c|c|c|c|c|c|c|}
\hline \multirow[t]{3}{*}{ Variables } & \multicolumn{2}{|c|}{ All patients } & \multicolumn{4}{|c|}{ Patients using ART } & \multirow[t]{3}{*}{ p-value } \\
\hline & \multirow[b]{2}{*}{$\mathbf{N}$} & \multirow[b]{2}{*}{$\%$} & \multicolumn{2}{|c|}{ Yes } & \multicolumn{2}{|c|}{ No } & \\
\hline & & & $\mathbf{N}$ & $\%$ & $\mathbf{N}$ & $\%$ & \\
\hline \multicolumn{8}{|l|}{ Initial staging } \\
\hline Low risk & 3 & 13.6 & 2 & 28.6 & 1 & 6.7 & 0.227 \\
\hline High risk & 19 & 86.4 & 5 & 71.4 & 14 & 93.3 & \\
\hline \multicolumn{8}{|l|}{ Outcome } \\
\hline Complete remission & 9 & 40.9 & 2 & 28.6 & 7 & 46.7 & 0.346 \\
\hline Partial remission & 1 & 4.5 & 0 & - & 1 & 6.7 & \\
\hline Stable disease & 1 & 4.5 & 1 & 14.3 & 0 & - & \\
\hline Disease progression & 2 & 9.1 & 0 & - & 2 & 13.3 & \\
\hline Cure & 1 & 4.5 & 0 & - & 1 & 6.7 & \\
\hline Death & 8 & 36.5 & 4 & 57.1 & 4 & 26.7 & \\
\hline
\end{tabular}

were not. There was no significant association between the initial staging and the use of ART (Table 4).

Regarding the outcome of Kaposi's sarcoma after treatment with chemotherapy + ART or exclusive ART, 40.9\% (9/22) of patients had complete remission, and in one case the remission was partial. One case presented stable disease; in two cases, the disease progressed; and in one case, there was healing after five years. Among the researched cases, eight died (36.5\%), seven in the first year of treatment and one death after the first year. Associating the outcome of the case with the use of ART, there was no statistical significance, in which it was observed that the distribution of outcomes was similar between patients with and without ART use (Table 4).

\section{DISCUSSION}

$\mathrm{KS}$ is a multifocal malignant neoplasm resulting from the abnormal proliferation of the vascular endothelium, which occurs mainly in individuals with immune deficiency, and this cancer is most commonly associated with AIDS. Since its initial description by the Hungarian dermatologist Moritz Kaposi, remains a clinical and therapeutic challenge. ${ }^{9}$ After the introduction of ART in the mid-1990s, there was a significant decline of this neoplasia in developed countries, a fact not observed in the emerging countries where KS remains with high incidence and high mortality rate. ${ }^{10,11}$
In a study published by Saraceni et al. in 2013, the prevalence of KS decreased after the introduction of ART in all regions of Brazil, suggesting an individual protection of the antiretroviral medication. ${ }^{12}$

Regarding the demographic characteristics, a predominance of the male population was observed, a result similar to other studies. ${ }^{12}$ This is probably due to the high frequency of human herpes virus type 8 (HHV 8) infection, also called KS-associated herpes virus (KSHV) in men who have sex with men (MSM), a group predominantly affected by HIV infection in Brazil and in the state of Pernambuco. ${ }^{13-15}$ Mean age was 33 years, with $32 \%$ of the patients being under 25 years of age. This finding may be partly explained by the shift in the diagnosis of HIV/AIDS infection to younger age groups, particularly in Northeast Brazil. Recent data from the Ministry of Health show that most new HIV infections occur in men who have sex with men (MSM) under the age of 25 years. ${ }^{13}$

More than half of the patients had a T-CD4+ cell count below 200 cells $/ \mathrm{mm}^{3}$, in agreement with most studies found where the mean T-CD4+ cell count was below 200 cells $/ \mathrm{mm}^{3} .{ }^{16-18}$ In a retrospective comparative analysis conducted at the Evandro Chagas National Institute of Infectious Diseases in Rio de Janeiro and at the Comprehensive Care Center for HIV/AIDS patients in Nashville, it was shown that immunosuppression was associated with an increased risk of developing neoplasias defining AIDS. ${ }^{19}$

This fact signs for late diagnosis of HIV infection, often only when there are opportunistic infections or neoplasms such as KS. Most of the research subjects did not use ART at the time of KS diagnosis, demonstrating that, despite the educational campaigns and universal availability of ART, those most vulnerable to infection still delay its diagnosis and treatment. ${ }^{20}$

In the present study, the cutaneous lesions were predominant in the individuals, being the disseminated form the most observed, and when there was involvement of deep organs, the stomach was the most affected. Similar results were described by Rezende $e$ al. in a retrospective study with patients presenting KS in stomach, of which $80 \%$ had concomitant skin lesions. ${ }^{21}$ On the other hand, in a survey conducted in the city of Rio de Janeiro/Brazil by Corriça \& Caldas, the involvement of skin and organs was lower, reaching around $54.8 \%{ }^{22}$

Although the presence of KS in the oral cavity is particularly common and may be the initial symptom of the disease, ${ }^{23}$ these findings were only observed in five of the 22 patients, reinforcing that the cutaneous manifestations represented the most common presentation form of the neoplasia. Many of these patients with characteristic skin lesions reported care by a non-dermatologist physician months before the definitive diagnosis of the disease, and that they did not recognize KS. An unusual finding observed was exclusive visceral involvement without skin or palate lesions in two patients, corroborating findings reported in the literature. ${ }^{24}$ In such cases, the diagnosis of KS can be difficult due to systemic manifestations and may lead to confusion with other diseases, especially in the scenario of a compromised immune system..$^{25}$

Because a large number of individuals had T-CD4+ cells $<200$ cells $/ \mathrm{mm}^{3}$, some opportunistic infections were observed at the time of KS diagnosis. Oroesophageal candidiasis was the most diagnosed opportunistic infection in this group of individuals, fol- 
lowed by pulmonary and extrapulmonary tuberculosis. Similar results were demonstrated by Keller et al. in a multicenter study in which it was shown that the most frequent opportunistic infections in patients with KS were oroesophageal candidiasis followed by pulmonary and extrapulmonary tuberculosis. ${ }^{26}$ These findings point to the late diagnosis of HIV infection, and to the fact still not explained that these patients present a higher risk of tuberculosis than the general population.

In the literature, ART use has been associated with a substantial decline in the incidence of KS among AIDS patients. ${ }^{27-29}$ This can be explained both by the direct action of ART on KSHV as well as by the suspension of the progression of HIV infection and, consequently, the immunodeficiency that predisposes KS. In case series, few patients used ART at the time of KS diagnosis, similar to the data found by Saraceni et al, in which $57 \%$ of KS cases were diagnosed before the individual started antiretroviral treatment. ${ }^{12}$ Among individuals not using ART, many presented old - but newly diagnosed - HIV infections. De Boer et al, in a survey conducted in South Africa with 161 patients, describes the relation of delayed diagnosis of HIV and the presence of advanced KS. ${ }^{11}$

Regarding KS treatment, most (17/22) subjects underwent treatment with ART associated with chemotherapy, while only five were treated exclusively with ART. The subjects had their treatment conducted in a university hospital in one of the poorest regions of Brazil, where, despite the limitations, almost half of the individuals (46.6\%) were treated with liposomal doxorubicin, and the other part was treated with combined regimen of BV (bleomycin-vincristine) or ABV (adriamycin-bleomycin-vincristine). When the combined regimen chosen was $\mathrm{BV}$ over $\mathrm{ABV}$, the choice was made because many patients had KS at later stages of the disease, with low immunity, presence of opportunistic diseases, and a Karnofsky Performance Status $<70$.

In this study, despite the late diagnosis of KS associated with AIDS in the studied population, including unfavorable risk at the time of staging, a lower mortality rate $(36.5 \%)$ was found than that reported by Chu et al. in a study conducted in South Africa, where the mortality rate was 70/100 person years (95\% CI 42-117). ${ }^{10}$ This relative low lethality can be explained, in part, by the fact that these patients attend specialized health services.

\section{CONCLUSION}

The findings of the present study allow a better clinical-epidemiological understanding of the clinical staging and outcome of KS cases associated with AIDS in our region. The research points to a population of men who have sex with men, young, with an advanced state of immunodepression, reflected in the prevalence of disseminated lesions and opportunistic infections associated with KS. It is important to note that the fact that the study was conducted inan universitu hospital may have directed a sample of more serious cases and that, despite this fact, the availability of chemotherapy with first-line drugs may have influenced a lower mortality than that reported in the literature, even though there is a delay in the diagnosis and treatment of KS.]

\section{ACKNOWLEDGEMENTS}

We thank the teams of the Oncology, Dermatology and Infectious and Parasitic Diseases Services of the Hospital das Clínicas of the UFPE for collaborating with the clinical data of the cases studied, enabling this research.

\section{REFERENCES}

1. Stefan DC, Stones DK, Wainwright L, Newton R. Kaposi Sarcoma in South African children. Pediatr Blood Cancer. 2011;56:392-6.

2. Engels EA, Pfeiffer RM, Goedert JJ, Virgo P, McNeel TS, Scoppa SM, et al. HIV/ AIDS Cancer Match study. Trends in cancer risk among people with AIDS in the United States 1980-2002. AIDS. 2006;20:1645-54.

3. Lucia MB, Anu R, Handley M, Gillet JP, Wu CP, De Donatis GM, et al. Exposure to HIV-protease inhibitors selects for increased expression of P-glycoprotein (ABCB1) in Kaposi's sarcoma cells. Br J Cancer. 2011;105:513-22.

4. La Ferla L, Pinzone MR, Nunnari G, Martellotta F, Lleshi A, Tirelli U, et al. Kaposi's sarcoma in HIV-positive patients: the state of art in the HAART-era. Eur Rev Med Pharmacol Sci. 2013;17:2354-65.

5. Gbabe OF, Okwundu $\mathrm{Cl}$, Dedicoat M, Freeman EE.. Treatment of severe or progressive Kaposi's sarcoma in HIV- infected adults. Cochrane Database Syst Rev. 2014:CD003256.

6. Who.int [Internet]. World Health Organization. The Progress report 2011: Global HIV/aids response [cited 2015 Jul 20 ). Available from: www.who.int/hiv/ pub/ progress_report2011/en/

7. Keller R, Zago A, Viana MC, Bourboulia D, Desgranges C, Casseb J, et al. HHV-8 infection in patients with AIDS-related Kaposi's Sarcoma in Brazil. Braz J Med Biol Res. 2001;34:879-86.

8. Ramos-da-Silva S, Elgui-de-Oliveira D, Borges L, Bacchi CE. Kaposi's Sarcomaassociated herpes virus infection and Kaposi's Sarcoma in Brazil. Braz J Med Biol Res. 2006;39:573-80.

9. Braun M. Classics in Oncology. Idiopathic multiple pigmented sarcoma of the skin by Kaposi. CA Cancer J Clin. 1982;32:340-7.
10. Chu KM, Mahlangeni G, Swannet S, Ford NP, Boulle A, Van Cutsem G. AIDSassociated Kaposi's Sarcoma is linked to advanced disease and high mortality in a primary care HIV programme in South Africa. J Int AIDS Soc. 2010;13:23.

11. De Boer C, Niyonzima N, Orem J, Bartlett J, Zafar SY. Prognosis and delay of diagnosis among Kaposi's sarcoma patients in Uganda: A cross-sectional study. Infect Agent Cancer. 2014;9:17.

12. Saraceni V, Talhari CC, Pereira GF, Golub JE, Talhari S, Miranda AE. AIDS-related Kaposi's sarcoma in Brazil: trends and geopolitical distribution. Int J Dermatol. 2013;52:1525-9.

13. Ministério da Saúde. Secretaria de Vigilância em Saúde. Departamento de DST, Aids e Hepatites Virais. Boletim epidemiológico HIV/AIDS. Brasília: Ministério da Saúde; 2015. Ano IV - no 1. Available from: http://www.aids.gov.br/sites/default/ files/anexos/publicacao/2015/58534/boletim_aids_11_2015_web_pdf_19105.pdf

14. Tiussi RM, Caus AL, Diniz LM, Lucas EA. Kaposi Sarcoma: clinical and pathologica aspects in patients seen at the Hospital Universitário Cassiano Antonio MoraesVitória- Espírito Santo- Brazil. An Bras Dermatol. 2012;87:220-7.

15. Leão JC, Hinrichsen SL, De Freitas BL, Poter SR. Herpes Vírus Humano 8 e Sarcoma de Kaposi. Rev Ass Med Brasil. 1999;45:55-62.

16. Maskew M, Fox MP, van Cutsem G, Chu K, Macphail P, Boulle A, et al. Treatment response and mortality among patients starting antirretroviral therapy with and without Kaposi Sarcoma: A cohort study. PLoS One. 2013;8:e64392.

17. Nelson BC, Borok MZ, Mhlanga TO, Makadzange AT, Campbell TB. AIDSassociated Kaposi Sarcoma: Outcomes after initiation of antirretroviral therapy at a University-affiliated Hospital in Urban Zimbabwe. Int J Infect Dis. 2013;17:e902-6. 
18. Mwafongo AA, Rosenberg NE, Ng'ambi W, Werner AB, Garneau WM, Gumulira $J$, et al. Treatment outcomes of AIDS- associated Kaposi's Sarcoma under a routine antirretroviral therapy program in Lilongwe, Malawi; Bleomycin/ Vincristine compared to Vincristine monotherapy. PLoS One. 2014:9:e91020.

19. Castilho JL, Luz PM, Shepherd BE, Turner M, Ribeiro SR, Bebawy SS, et al. HIV and cancer: a comparative retrospective study of Brazilian and U.S. clinical cohorts. Infect Agent Cancer. 2015;10:4.

20. Grangeiro A, Escuder MM, Menezes PR, Alencar R, Ayres de Castilho E. Late entry into HIV care: Estimated impact n AIDS mortality rates in Brazil, 2003-2006. PLoS One. $2011 ; 6: \mathrm{e} 14585$.

21. Rezende RE, Kahwage RL, da Costa TV, Machado AA, Brunaldi MO, Kemp R, et al. Upper gastrointestinal Kaposi's sarcoma in HIV-infected patients: ten years of endoscopy observation at a single Brazilian center. Int J Infect Dis. 2015;39:110-5.

22. Corriça TMC, Caldas MLR. Kaposi's Sarcoma in aids cases: Study in 20 years of necropsy in University Hospital. DST - J Bras Doenças Sex Transm 2009:21: 9-11.

23. Dezube BJ, Pantanowitz L, Aboulafia DM. Management of AIDS-related Kaposi Sarcoma: advances in target Discovery and treatment. AIDS Read. 2004;14:2368, 243-4, 251-3.

24. Kibria R, Siraj U, Barde C. Kaposi's Sarcoma of the stomach and duodenum in human immunodeficiency virus infection. Dig Endosc. 2010;22:241-2.

25. Shepard B, Tompkins D, Baker D, Stroup J. Disseminated Kaposi's Sarcoma without cutaneous involvement. Proc (Bayl Univ Med Cent). 2014;27:31-2.

26. Keller R, Zago A, Viana MC, Bourboulia D, Desgranges C, Casseb J, et al. HHV-8 infection in patients with AIDS- related Kaposi's Sarcoma in Brazil. Braz J Med Biol Res. 2001;34:879-86.

27. Arruda É, Jacome AA, Toscano AL, Silvestrini AA, Rêgo AS, Wiermann EG, et al. Consensus of the Brazilian Society of Infectious Diseases and Brazilian Society of Clinical Oncology on the management and treatment of Kaposi's Sarcoma. Braz J Infect Dis. 2014;18:315-26.

28. Lodi S, Guiguet M, Costagliola D, Fisher M, de Luca A, Porter K; et al. The CASCADE collaboration Kaposi Sarcoma Incidence and Survival among HIV- Infected homossexual men after HIV seroconversion. J Natl Cancer Inst. 2010;102:784-92.

29. International Collaboration on HIV and Cancer. Highly active antirretroviral therapy and incidence of cancer in human immunodeficiency virus-infected adults. J Nat Cancer Inst. 2000:92:1823-30.
MAILING ADDRESS:

Catarina Tenório de Lima

Av. Prof. Moraes Rego, 1.235

Cidade Universitária

50670-901 - Recife - PE

Brazil

Email:catarina_tl@yahoo.com.br

How to cite this article: Lima CT, Araújo PSR, Teixeira HM, Santos JB, Magalhaes V. Clinical and laboratory characteristics, staging, and outcomes of individuals with AIDS-associated Kaposi's sarcoma at an university hospital. An Bras Dermatol. 2017;92(2):172-6. 